\title{
Projected 21st century changes in snow water equivalent over Northern Hemisphere landmasses from the CMIP5 model ensemble
}

\author{
H. X. Shi and C. H. Wang \\ Key Laboratory of Arid Climate Change and Disaster Reduction of Gansu Province, College of Atmospheric Sciences, \\ Lanzhou University, Lanzhou, 730000, China \\ Correspondence to: C. H. Wang (wch@1zu.edu.cn)
}

Received: 4 March 2015 - Published in The Cryosphere Discuss.: 30 March 2015

Revised: 17 September 2015 - Accepted: 25 September 2015 - Published: 13 October 2015

\begin{abstract}
Changes in snow water equivalent (SWE) over Northern Hemisphere (NH) landmasses are investigated for the early (2016-2035), middle (2046-2065) and late (20802099) 21 st century using a multi-model ensemble from 20 global climate models from the Coupled Model Intercomparison Project Phase 5 (CMIP5). The multi-model ensemble was found to provide a realistic estimate of observed $\mathrm{NH}$ mean winter SWE compared to the GlobSnow product. The multi-model ensemble projects significant decreases in SWE over the 21st century for most regions of the NH for representative concentration pathways (RCPs) 2.6, 4.5 and 8.5. This decrease is particularly evident over the Tibetan Plateau and North America. The only region with projected increases is eastern Siberia. Projected reductions in mean annual SWE exhibit a latitudinal gradient with the largest relative changes over lower latitudes. SWE is projected to undergo the largest decreases in the spring period where it is most strongly negatively correlated with air temperature. The reduction in snowfall amount from warming is shown to be the main contributor to projected changes in SWE during September to May over the NH.
\end{abstract}

\section{Introduction}

Snow is a key component of the cryosphere and plays a fundamental role in global climate due to its high albedo and cooling effect (Vavrus, 2007). Snow cover represents a spatially and temporally integrated response to snowfall events (Brown and Mote, 2009), and is closely related to air temperature at the hemispheric scale (Brutel-Vuilmet et al., 2013).
Marked decreases in the area and/or depth of snow have been documented in many regions of the Northern Hemisphere including western North America (Groisman et al., 2004; Stewart et al., 2005), central Europe (Falarz, 2002; Vojtek et al., 2003; Scherrer et al., 2004) and China (Ji and Kang, 2012; Wang and Wang, 2012). Satellite data show that Northern Hemisphere (NH) terrestrial snow cover extent has experienced significant decreases from earlier melt over the period from $\sim 1970$ (Vaughan et al., 2013), and this trend is projected to continue in the future with an estimated projected decrease in $\mathrm{NH}$ spring snow cover of $25 \%$ by the end of the 21st century for representative concentration pathway (RCP) RCP8.5 (Collins et al., 2013).

Snow water equivalent (SWE) represents the water stored in the snowpack and is a key variable for climate and hydrological applications. Locally SWE responds to both precipitation and air temperature which are both projected to increase in the 21st century (Collins et al., 2013) and the magnitude and seasonal character of the change represents a complex interplay between a shortened snow accumulation period, the fraction of precipitation that falls as snow (influenced by total precipitation and air temperature) and the frequency and intensity of winter thaw events (Räisänen, 2008; Brown and Mote, 2009).

Räisänen (2008) showed that projected winter SWE change over the $\mathrm{NH}$ could be approximately divided into increasing and decreasing zones based on the $-20{ }^{\circ} \mathrm{C}$ isotherm for November-March air temperature, with increasing SWE only observed over very cold regions. This temperature dependence is also evident in the elevation response of SWE in mountain regions with the largest SWE decreases projected over lower elevations (Maloney et al., 2014) and projected in- 


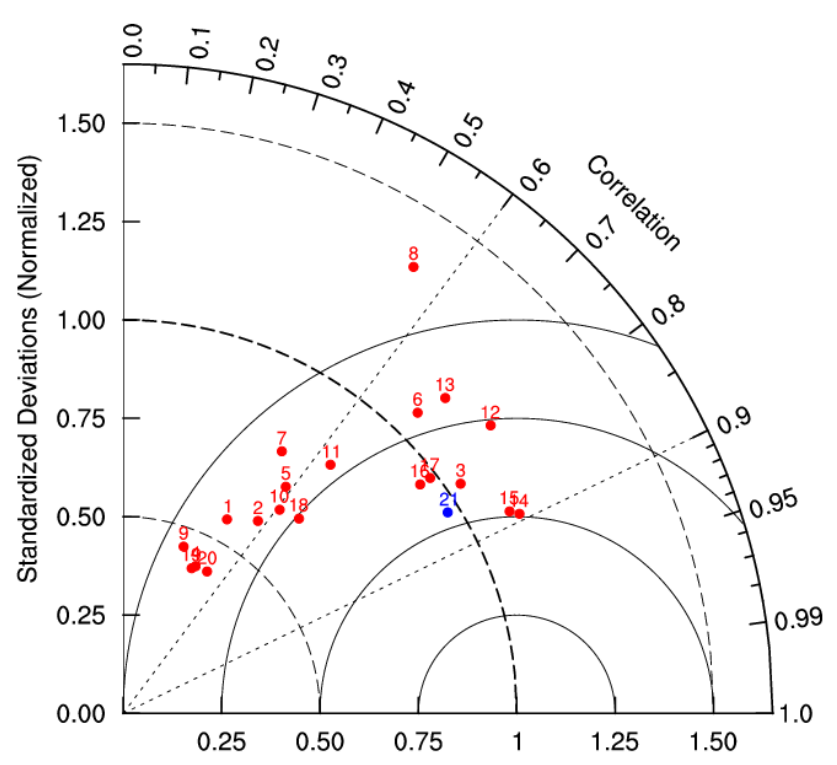

Figure 1. Spatial correlation and standard variance ratios between observed and simulated winter (DJF - December-JanuaryFebruary) mean SWE during 1980-2005. The numbers 1-20 refer to the model names in Table 1 . The number 21 indicates the multimodel ensemble. The vertical axis indicates the standard deviation ratios, and the numbers along the arc are the spatial correlation.

crease in SWE over high elevations in some regions (Scherrer et al., 2004; Mote et al., 2005; Mote, 2006).

Previous studies showed that climate models (GCMs) can well reproduce basic properties of the snow cover (depth, SWE; Wang et al., 2009; Wang et al., 2010; Zhu and Dong, 2013; Brutel-Vuilmet et al., 2013). However, the seasonal response of SWE to a warming climate has not been addressed in much detail as previous studies have tended to focus on winter season or annual maximum SWE. The main objective of this paper is to provide additional insights into the spatial and temporal characteristics of projected SWE change over the NH by addressing the following two questions. (1) How will NH SWE respond to different RCPs in the 21st century (i.e. the magnitude, timing and spatial and seasonal character of the projected changes)? (2) What are the relative contributions of air temperature and precipitation to the projected SWE change over the 21 st century?

These questions were assessed using output from the CMIP5 archive (Taylor et al., 2012; http://www-pcmdi.llnl. gov) for emission scenarios RCP2.6, 4.5 and 8.5. The fidelity of model-simulated NH SWE was assessed with the GlobSnow (V2.0) product. We focus primarily on temporal and spatial changes in SWE and on variations in the relationship between SWE and climate for each RCP during different periods of the 21st century. The specific data sets used in this study are described in Sect. 2, and the simulated and observed data are compared in Sect. 3. The temporal and spatial characteristics of SWE projections are analyzed in Sect. 4,

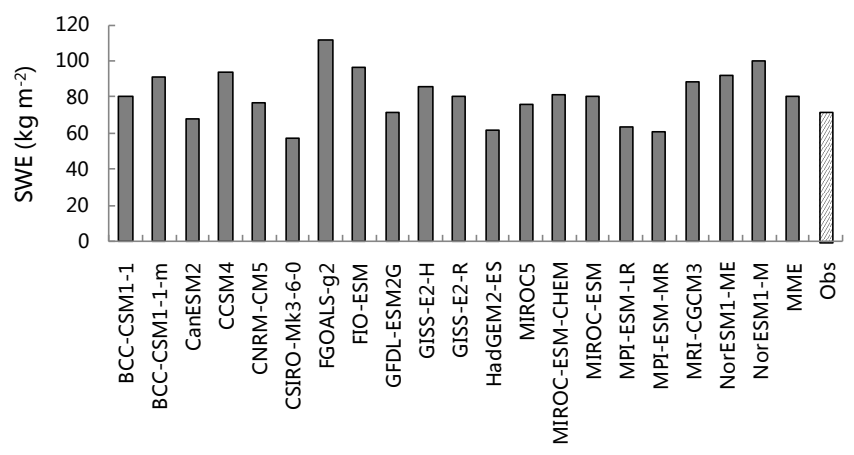

Figure 2. The average of the observed and simulated winter (DJF) mean SWE over non-mountain land areas of the Northern Hemisphere during 1980-2005. The multi-model ensemble (MME) refers to a combination of the 20 models listed in Table 1.

and the relationships between SWE and climate change are discussed in Sect. 5. Finally, the key findings of the study are summarized in Sect. 6.

\section{Data sets}

To objectively quantify the changes in SWE in the 21st century, we examined 20 models participating in CMIP5 (Table 1) with monthly SWE output for the historical and three RCP scenarios analyzed (RCP2.6, RCP4.5 and RCP8.5). Output from run1 of each model was used (e.g., r1i1p1).

Monthly SWE output for the three RCPs for the 20062099 period were used and averages computed over three sub-periods to evaluate change: an early (2016-2035; EP), middle (2045-2065; MP) and late period (2080-2099; LP). Model output was regridded (bilinear interpolation) to a $1^{\circ} \times 1^{\circ}$ latitude-longitude grid for the analysis.

The fidelity of the SWE simulations from the CMIP5 models was evaluated with monthly SWE data from the European Space Agency (ESA) GlobSnow (version 2) product (Takala et al., 2011). GlobSnow combines SWE retrieved from passive microwave and weather station snow depth observations. This is the most realistic SWE product currently available (Hancock et al., 2013) because of the improved accuracy achieved by assimilating in situ snow observations into the passive microwave SWE retrieval process. The GlobSnow SWE series cover the period 1979-2010 at a resolution of $25 \times 25 \mathrm{~km}$, and were also interpolated to the common $1^{\circ} \times 1^{\circ}$ grid. Hereafter, we refer to the GlobSnow data set as the observed SWE. The GlobSnow product is masked out over mountainous regions due to well-documented uncertainties in SWE retrievals over complex terrain (Tong et al., 2010). The model evaluation/comparison was carried out over the non-masked grid points.

In this paper, linear correlation coefficients, partial correlation analysis and regression analysis are used to investigate the relation between model simulated SWE and observation 
Table 1. Models information used in this study.

\begin{tabular}{|c|c|c|c|}
\hline Number & Model & Institution & Resolution \\
\hline 1 & BCC-CSM1-1* & Beijing Climate Center, China & $2.8^{\circ} \times 2.8^{\circ}$ \\
\hline 2 & BCC-CSM1-1(m)* & Beijing Climate Center, China & $1.3^{\circ} \times 1.1^{\circ}$ \\
\hline 3 & CanESM2* & $\begin{array}{l}\text { Canadian Center for Climate Modeling } \\
\text { and Analysis, Canada }\end{array}$ & $2.8^{\circ} \times 2.8^{\circ}$ \\
\hline 4 & CCSM4 & National Center for Atmospheric Research, USA & $1.25^{\circ} \times 0.94^{\circ}$ \\
\hline 5 & CNRM-CM5 & $\begin{array}{l}\text { Centre National de Recherches Meteorologiques/ } \\
\text { Centre Européen de Recherche et } \\
\text { Formation Avancée en Calcul Scientifique }\end{array}$ & $1.4^{\circ} \times 1.4^{\circ}$ \\
\hline 6 & CSIRO-Mk3-6-0* & CSIRO Atmospheric Research, Australia & $1.875^{\circ} \times 1.875^{\circ}$ \\
\hline 7 & FGOALS-g2 & Chinese Academy of Sciences & $1.4^{\circ} \times 6^{\circ}$ \\
\hline 8 & FIO-ESM & The First Institute of Oceanography, SOA, China & $2.8^{\circ} \times 2.8^{\circ}$ \\
\hline 9 & GFDL-ESM2G* & Geophysical Fluid Dynamics Laboratory, USA & $2.5^{\circ} \times 2.0^{\circ}$ \\
\hline 10 & GISS-E2-H & ASA Goddard Institute for Space Studies, USA & $2.5^{\circ} \times 2.0^{\circ}$ \\
\hline 11 & GISS-E2-R & NASA Goddard Institute for Space Studies, USA & $2.5^{\circ} \times 2.0^{\circ}$ \\
\hline 12 & HadGEM2-ES* & Met Office Hadley Centre, UK & $1.875^{\circ} \times 1.25^{\circ}$ \\
\hline 13 & MIROC5 & Atmosphere and Ocean Research Institute, Japan & $1.4^{\circ} \times 1.4^{\circ}$ \\
\hline 14 & MIROC-ESM-CHEM & $\begin{array}{l}\text { Japan Agency for Marine-Earth Science and Technology, } \\
\text { Atmosphere and Ocean Research Institute, Japan }\end{array}$ & $2.8^{\circ} \times 2.8^{\circ}$ \\
\hline 15 & MIROC-ESM & $\begin{array}{l}\text { Japan Agency for Marine-Earth Science and } \\
\text { Technology, Atmosphere and Ocean Research Institute, Japan }\end{array}$ & $2.8^{\circ} \times 2.8^{\circ}$ \\
\hline 16 & MPI-ESM-LR* & Max Planck Institute for Meteorology, Germany & $1.9^{\circ} \times 1.9^{\circ}$ \\
\hline 17 & MPI-ESM-MR* & Max Planck Institute for Meteorology, Germany & $1.875^{\circ} \times 1.875^{\circ}$ \\
\hline 18 & MRI-CGCM3 & Meteorological Research Institute, Japan & $1.1^{\circ} \times 1.1^{\circ}$ \\
\hline 19 & NorESM1-ME & Norwegian Climate Center, Norway & $2.5^{\circ} \times 1.875^{\circ}$ \\
\hline 20 & NorESM1-M & Norwegian Climate Center, Norway & $2.5^{\circ} \times 1.875^{\circ}$ \\
\hline
\end{tabular}

Note that * indicates the model's simulation agrees well with observation (GlobSnow) in summer during the reference period.

(GlobSnow), and the simulated SWE and temperature, precipitation from different scenario experiments. The equations are as follows.

Partial correlation:

$r_{X Y, Z}=\frac{r_{X Y}-r_{X Z} r_{Y Z}}{\sqrt{\left(1-r_{X Z}^{2}\right)\left(1-r_{Y Z}^{2}\right)}}$,

where $r_{X Y, Z}$ indicates the contribution of $X$ to $Y$, after removing the contribution of $Z$ to $Y$.

Regression coefficient:

$Y=b+a t$,

where $a$ represents the linear trend of factor $Y$ with time $t$.

Relative change $(\mathrm{RC})$ rate:

$\mathrm{RC}=\frac{S_{i}-O_{i}}{O_{i}} \cdot 100 \%$,

where RC reflects the change in a variable $S$ relative to the baseline $O$.

Räisänen (2008) decomposed change in SWE ( $\Delta$ SWE) into four terms:

$\Delta \mathrm{SWE}=\underbrace{\bar{G} \int \bar{F} \Delta P \mathrm{~d} t}_{\Delta \operatorname{SWE}(\Delta P)}+\underbrace{\bar{G} \int \Delta F \bar{P} \mathrm{~d} t}_{\Delta \operatorname{SWE}(\Delta F)}+\underbrace{\Delta G \int \bar{F} \bar{P} \mathrm{~d} t}_{\Delta \operatorname{SWE}(\Delta G)}+\underbrace{\frac{1}{4} \Delta G \int \Delta F \Delta P \mathrm{~d} t}_{\Delta \mathrm{SWE}(\mathrm{NL})}$, where the first three terms on the right represent the contribution from changes in total precipitation $(\Delta P)$, fraction of solid precipitation $(\Delta F)$ and the fraction of accumulated snowfall that remains on the ground $(\Delta G) . \Delta \mathrm{SWE}(\mathrm{NL})$ is a non-linear combination of $\Delta G, \Delta F$ and $\Delta P . P_{1}$ is mean total precipitation during different periods of the 21 st century, which includes solid precipitation and liquid precipitation, and $P_{0}$ is the mean total precipitation during 1986 2005. By further introducing the notation, $\bar{P}=\left(P_{0}+P_{1}\right) / 2$, $\Delta P=\left(P_{1}-P_{0}\right), \bar{P}$ similar a mean state for two periods, the definitions of $\bar{G}, \Delta G, \bar{F}, \Delta F$ can refer to $\bar{P}, \Delta P$.

\section{Validation of CMIP5 SWE simulations}

The fidelity of the model-simulated mean winter SWE was analyzed by constructing a Taylor diagram (Taylor, 2001) for the observed and simulated winter (DJF - DecemberJanuary-February) mean SWE (Fig. 1) over the 1980-2005 period. While all the models exhibited statistically significant correlations to the mean SWE field, the results show a wide range in model performance and one clear outlier (FIO-ESM). There was no evidence that model resolution affected performance as the cluster of models with better evaluation results (CanESM2, CCSM4, FGOALS-g2, MIROC- 


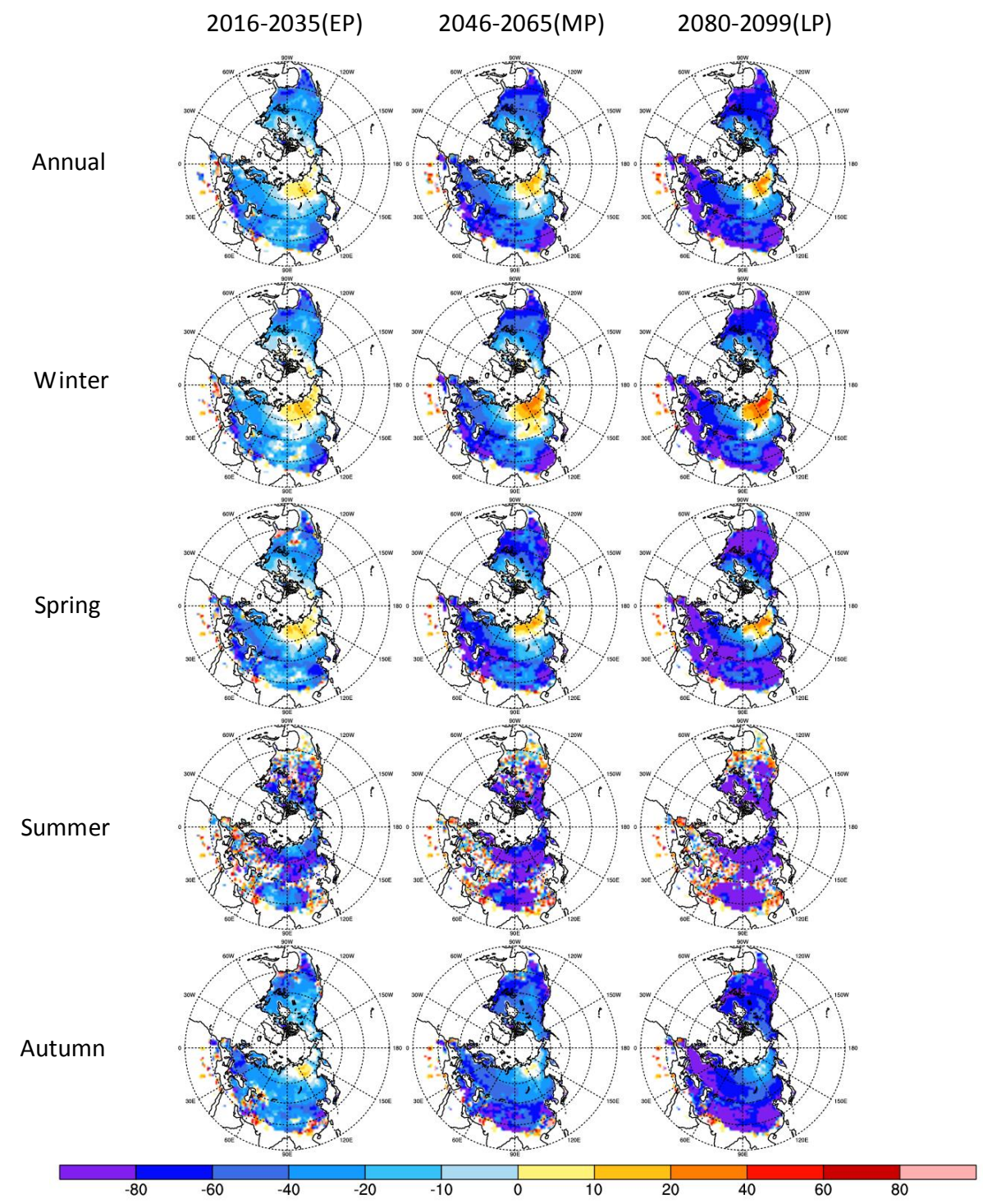

Figure 3. Projected relative change in mean annual and seasonal SWE (\% relative to 1986-2005 reference period) by the CMIP5 ensemble for RCP8.5. The shade area indicates the change exceeds $95 \%$ significant level.

ESM and MPI-ESM-LR) cover a wide range of model resolutions. The multi-model ensemble (blue dot in Fig. 1) provided better agreement with the observed mean SWE field than most models.

Figure 2 shows the observed and simulated mean winter SWE over NH land covered by the GlobSnow data. The observed mean winter SWE is $71.6 \mathrm{~kg} \mathrm{~m}^{-2}$, while the model simulations range from 61.0 to $111.3 \mathrm{~kg} \mathrm{~m}^{-2}$ with a multi-model ensemble average of $80.8 \mathrm{~kg} \mathrm{~m}^{-2}$ which agrees closely with the estimate of $82.3 \mathrm{~kg} \mathrm{~m}^{-2}$ for mean March SWE provide by Takala et al. (2011). From here on, all reported simulation values are from the multi-model ensemble mean, and we take the period 1986-2005 from the historical experiment (1850-2005) as the reference period.

\section{Changes in SWE in the 21st century}

To examine the future spatial and temporal characteristics of SWE, the relative change in the winter (DJF), spring (MAM - March-April-May), summer (JJA - June-July-August), autumn (SON) and annual SWE were calculated with Eq. (3) relative to the reference period (1986-2005).

\subsection{Spatial changes in SWE for three RCPs}

Projected spatial changes in mean annual and seasonal SWE relative to the 1986-2005 reference period (RP) for the three previously defined sub-periods of the 21 st century are shown in Fig. 3 for RCP 8.5. These plots show that projected SWE changes scale with time. The mean annual SWE declines 
(a)

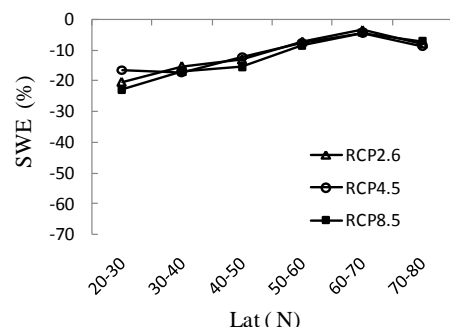

(d)

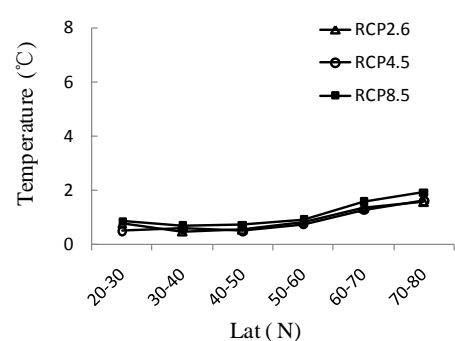

(g)

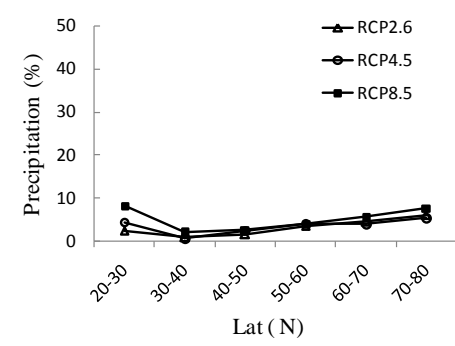

(b)

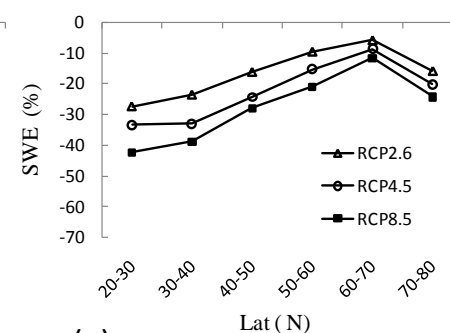

(e)

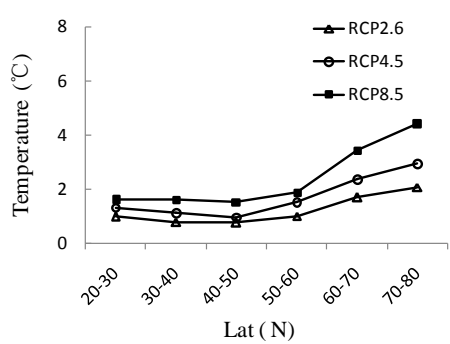

(h)

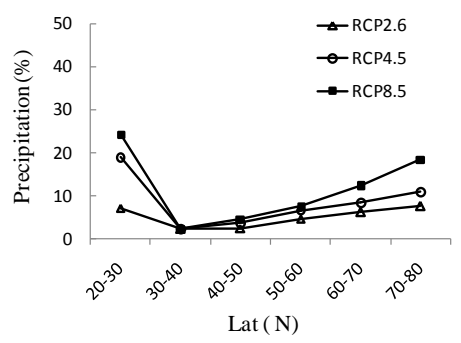

(c)

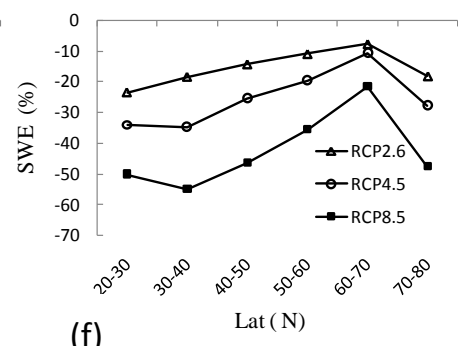

(f)

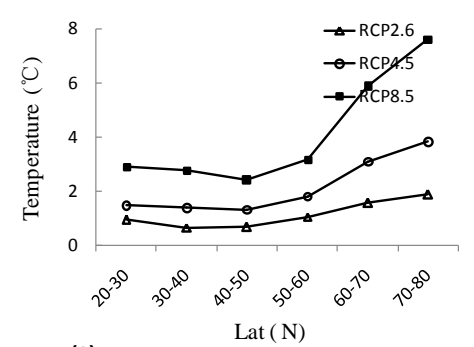

(i)

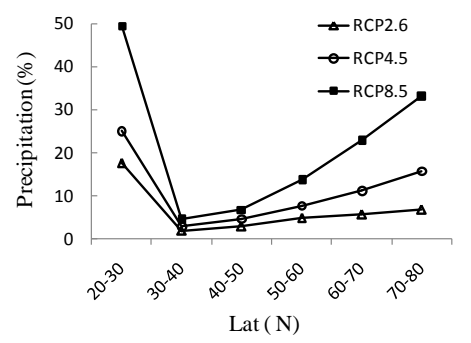

Figure 4. Projected change in zonally averaged mean annual SWE (a-c), mean annual air temperature (d-f) and mean annual precipitation (g-i) over Northern Hemisphere land for 2016-2035 (left), 2046-2065 (middle), and 2080-2099 (right) relative to the 1986-2005 reference period.

Table 2. Zonally averaged slope (Slop, $\mathrm{kg} \mathrm{m}^{-2}{ }^{\circ} \mathrm{C}^{-1}$ ) and correlation (Cor.) from the regression of mean annual SWE and temperature for three RCPs. RP, EP, MP, and LP represent the periods 1986-2005, 2016-2035, 2046-2065, and 2080-2099, respectively.

\begin{tabular}{|c|c|c|c|c|c|c|c|c|c|c|c|}
\hline \multirow[b]{2}{*}{$\operatorname{Lat}\left({ }^{\circ} \mathrm{N}\right)$} & & \multirow[b]{2}{*}{$\mathrm{RP}$} & \multicolumn{3}{|c|}{ RCP2.6 } & \multicolumn{3}{|c|}{ RCP4.5 } & \multicolumn{3}{|c|}{ RCP8.5 } \\
\hline & & & EP & MP & LP & EP & MP & LP & EP & MP & LP \\
\hline \multirow{3}{*}{ 20-30 } & Slop & $-0.43^{*}$ & -0.22 & -1.45 & -0.36 & $-0.52^{*}$ & -0.25 & -0.08 & $-0.23^{*}$ & $-0.23^{*}$ & -0.08 \\
\hline & Cor. & $-0.55^{*}$ & -0.22 & $-0.42^{*}$ & -0.14 & $-0.69^{*}$ & -0.34 & -0.03 & $-0.45^{*}$ & $-0.48^{*}$ & -0.30 \\
\hline & Slop & $-2.15^{*}$ & $-4.38^{*}$ & -0.74 & -1.02 & $-3.39^{*}$ & -0.85 & -2.86 & $-3.14^{*}$ & $-1.64^{*}$ & $-0.81^{*}$ \\
\hline \multirow[t]{2}{*}{$30-40$} & Cor. & $-0.64^{*}$ & $-0.91^{*}$ & -0.13 & -0.13 & $-0.77^{*}$ & -0.29 & -0.25 & $-0.84^{*}$ & $-0.78^{*}$ & $-0.68^{*}$ \\
\hline & Slop & $-1.00^{*}$ & -0.84 & -1.60 & $-2.97^{*}$ & $-1.69^{*}$ & $-1.06^{*}$ & $-3.02^{*}$ & $-1.77^{*}$ & $-0.89^{*}$ & $-0.76^{*}$ \\
\hline \multirow[t]{2}{*}{$40-50$} & Cor. & $-0.62^{*}$ & $-0.44^{*}$ & -0.39 & $-0.55^{*}$ & $-0.80^{*}$ & $-0.48^{*}$ & $-0.71^{*}$ & $-0.86^{*}$ & $-0.74^{*}$ & $-0.82^{*}$ \\
\hline & Slop & $-3.27^{*}$ & $-3.82^{*}$ & -0.39 & -2.68 & $-3.28^{*}$ & $-3.24^{*}$ & $-2.62^{*}$ & $-3.25^{*}$ & $-2.55^{*}$ & $-1.33^{*}$ \\
\hline \multirow[t]{2}{*}{$50-60$} & Cor. & $-0.71^{*}$ & $-0.64^{*}$ & -0.08 & -0.28 & $-0.75^{*}$ & $-0.65^{*}$ & $-0.57^{*}$ & $-0.80^{*}$ & $-0.78^{*}$ & $-0.67^{*}$ \\
\hline & Slop & $-2.87^{*}$ & $-2.57^{*}$ & -2.84 & -3.64 & $-3.67^{*}$ & $-5.10^{*}$ & -3.71 & $-4.10^{*}$ & $-3.70^{*}$ & $-2.84^{*}$ \\
\hline \multirow[t]{2}{*}{$60-70$} & Cor. & $-0.66^{*}$ & $-0.47^{*}$ & -0.32 & -0.33 & $-0.74^{*}$ & $-0.76^{*}$ & -0.35 & $-0.71^{*}$ & $-0.83^{*}$ & $-0.73^{*}$ \\
\hline & Slop & $-10.2^{*}$ & $-16.9^{*}$ & -0.30 & -2.40 & $-4.57^{*}$ & $-5.23^{*}$ & -2.10 & $-8.31^{*}$ & $-6.16^{*}$ & $-4.62 *$ \\
\hline 70-80 & Cor. & $-0.88^{*}$ & $-0.72^{*}$ & -0.02 & -0.35 & $-0.65^{*}$ & $-0.81^{*}$ & -0.06 & $-0.84^{*}$ & $-0.91^{*}$ & $-0.88^{*}$ \\
\hline
\end{tabular}

Note: * values exceed the $95 \%$ significance test. 


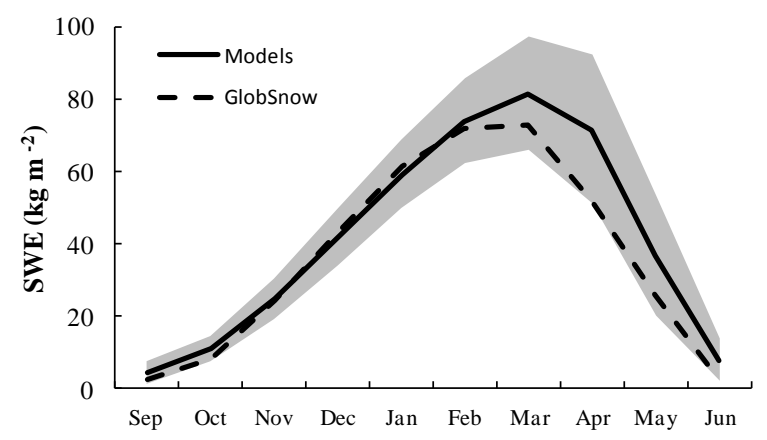

Figure 5. Area mean (1986-2005) seasonal cycle of SWE from eight models (asterisk-marked models in Table 1. dashed line for the multi-model mean and shading for \pm mean 1 standard deviation) and from the GlobSnow data.

over much of the $\mathrm{NH}$ for the three periods with the greatest declines (exceeding $80 \%$ ) occurring over the southern latitude during the MP and LP, there is another more significant reduction in SWE $(\mathrm{RC}>40 \%)$ over the Tibetan Plateau which is characterized by relatively shallow snow and more rapid increases in temperature than other mid-latitude areas (Liu and Chen, 2000; Chen et al., 2006; Wang et al., 2012). Pronounced reductions in SWE are also projected over Europe and North America (NA). The only region with projected significant increases in SWE is northern Siberia where winter SWE is projected to increase by up to $60 \%$ in the LP for RCP8.5. Projected decreases are largest along the southern limits of seasonal snow cover and in the shoulder seasons (spring, summer, fall), and the significant reduction (about $\mathrm{RC}>80 \%, P>95 \%$ ) in SWE in summer mainly concentrated over the high latitude. This suggests that the seasonal relative change in SWE depends on the baseline of snow.

Figure 4 illustrates the zonally averaged relative changes in mean annual SWE, precipitation and the absolute change in temperature derived from the multi-model mean for three periods of the 21 st century. Features of these plots are the amplification of warming over the Arctic (Pithan and Mauritsen, 2014), and the reduction in relative SWE decreases with increasing latitude up to $60-70^{\circ} \mathrm{N}$. The kink in the SWE curves above $70^{\circ} \mathrm{N}$ is likely related to the strong impact of declining sea ice cover on the snow cover season over coastal regions of the Arctic (AMAP 2011). The largest absolute changes in mean annual SWE (not shown) were found over high latitudes $\left(70-80^{\circ} \mathrm{N}\right)$, where is accompanied by the greater increase in temperature and precipitation.

The temperature sensitivity of projected SWE changes was investigated from linear regression analysis of annual SWE (dependent variable) and air temperature (independent variable) series over 10 latitudes zones for the RP, EP, MP and LP (Table 2). This analysis showed that air temperature was significantly negatively correlated to SWE in the RP and EP over most latitude bands, with the strength of the slope typically increasing with latitude. The strength and significance
Table 3. Trends in SWE over Northern Hemisphere land during 2006-2099 derived from the three RCPs. All trends are significant at $95 \%$ confidence level (Mann-Kendall test).

\begin{tabular}{lrrr}
\hline Trend & \multicolumn{3}{c}{ RCPs } \\
\cline { 2 - 4 }$\left(\mathrm{kg} \mathrm{m}^{-2} / 10 \mathrm{a}\right)$ & $\mathrm{RCP} 2.6$ & $\mathrm{RCP} 4.5$ & $\mathrm{RCP} 8.5$ \\
\hline Autumn & -0.51 & -1.17 & -1.83 \\
Winter & -0.54 & -1.18 & -2.18 \\
Spring & -0.61 & -1.32 & -2.39 \\
Summer & -0.50 & -1.09 & -1.79 \\
Mean & -0.54 & -1.19 & -2.05 \\
\hline
\end{tabular}

of the regression slope varies over time within each scenario depending on the interactions between the amount of warming and the change in snowfall. In RCP8.5 for example, warming effects dominate and significant negative slopes are observed over nearly all bands in all three time slices.

\subsection{Seasonal changes in SWE}

The multi-model ensemble basically reproduces the seasonal cycle in observed SWE(GlobSnow), Fig. 5 shows the comparisons of the monthly SWE from GlobSnow and simulation with ensemble result from eight models during the reference period (1986-2005). The models basically reproduce SWE and its variability, the models mean errors are less than $5 \%$ from November to February. However, the most models (12 of 20 models are not marked with asterisks in Table 1) overestimate monthly SWE in spring, it might be linked to the rapidly snowmelt with air temperature rising in spring, which implies the snow parameterization scheme in these models needs to be improved.

Figure 6 shows the absolute and relative change (RC) in SWE over NH land (excluding Greenland) during EP, MP and LP for all three RCPs relative to the RP of the 21st century. For all three periods of the 21 st century, the greatest decreases in SWE appears in snow season (Fig. 6a-c); considering the baseline of snow, on relative change, the greatest decreases in SWE occur during the snow season shoulder periods of June to October with the smallest reductions in February. The influence of emission scenario only becomes evident during the MP and LP (Fig. 6d-f). During the last period of the 21 st century (LP), the maximum reduction in SWE is $66.4 \%$ for RCP8.5, and ranges from $27.5 \%$ for RCP2.6 to $39.8 \%$ for RCP4.5. Consequently, the relative change in SWE is thus predicted to be markedly different to the absolute change.

Temperature and precipitation are the dominant parameters influencing SWE, and both exhibit considerable changes in seasonality (Fig. 7). Relative to the RP, temperatures are projected to rise during the EP (Fig. 7a), MP (Fig. 7b) and LP (Fig. 7c) for all three RCPs, with the greatest warming occurring in winter and the smallest in summer. The magni- 
(a)

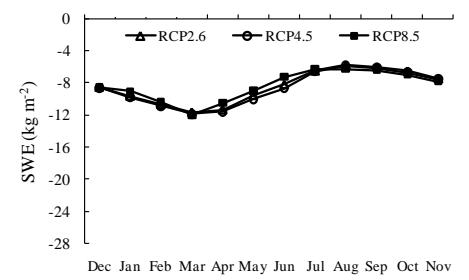

(d)

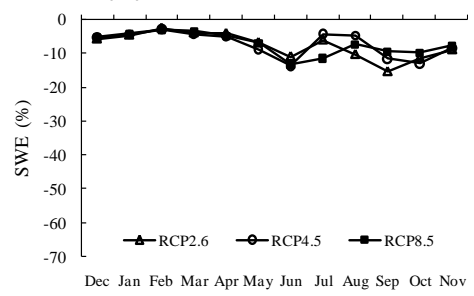

(b)

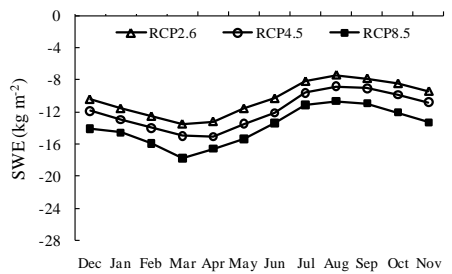

(e)

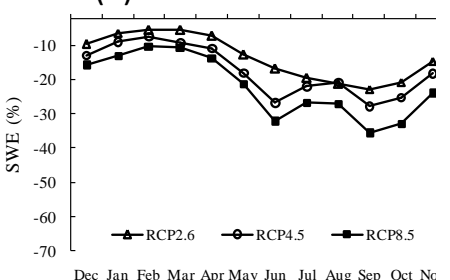

(c)

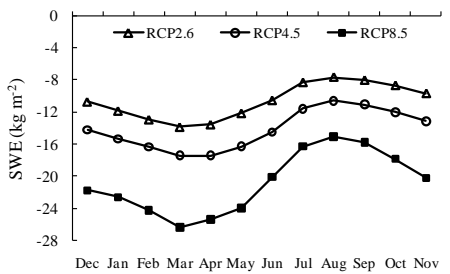

(f)

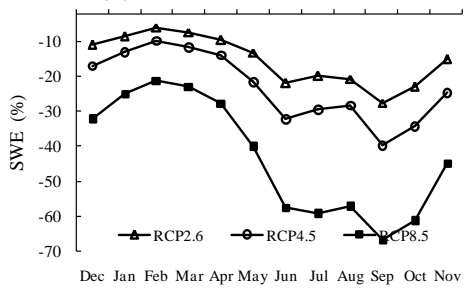

Figure 6. Projected absolute (a-c) and relative change (RC) (d-f) in monthly SWE over Northern Hemisphere land for 2016-2035 (left), 2046-2065 (middle), and 2080-2099 (right).

(a)

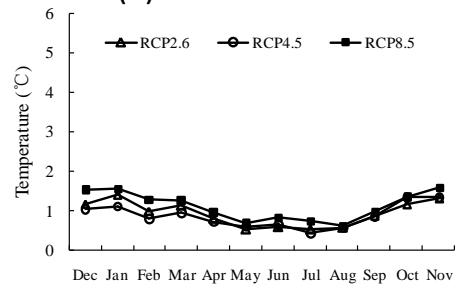

(d)

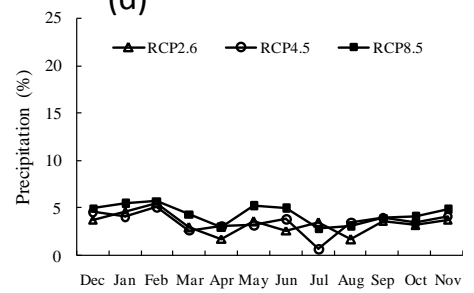

(b)

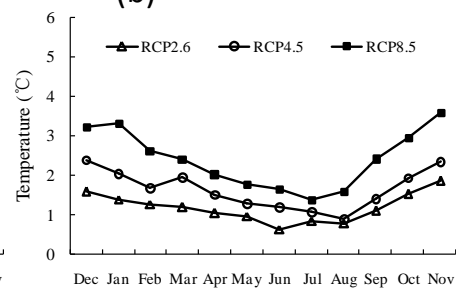

(e)

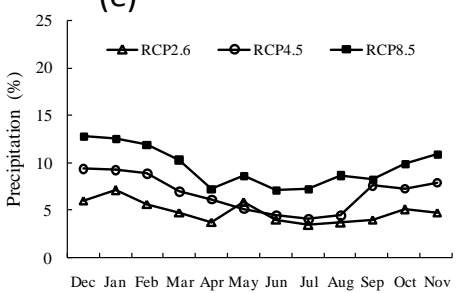

(c)

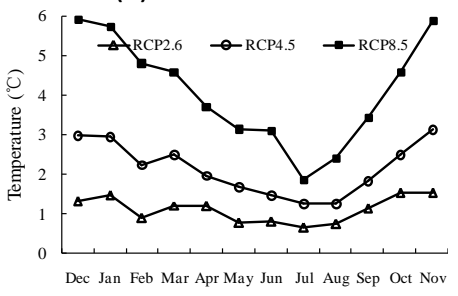

(f)

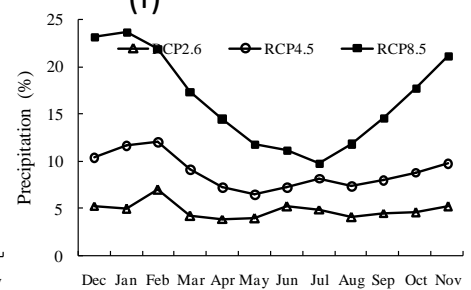

Figure 7. Changes in mean annual air temperature $(\mathbf{a}-\mathbf{c})$ and the relative change $(\mathrm{RC})$ in precipitation $(\mathbf{d}-\mathbf{f})$ over Northern Hemisphere land for 2016-2035 (left), 2046-2065 (middle), and 2080-2099 (right) for three RCPs, relative to the 1986-2005 reference period.

tude of the temperature change increases with higher emissions over time. In the EP, the temperature increase does not exceed $2{ }^{\circ} \mathrm{C}$ for all three RCPs, and larger differences emerge during the MP and LP. Moreover, a basic feature is that the temperature increase is significant in the high latitude during the three periods of 21 st century.

Precipitation also increases throughout the 21st century for all three RCPs (Fig. 7d-f), and changes in precipitation during winter exceed those during summer, despite the larger absolute change in precipitation in summer. During the EP, the magnitude of precipitation increase is the same for all three RCPs, and the change gradually grows larger with increased emissions over time. A noticeable feature of the model out- puts is that changes in precipitation for mid-low emissions are not significant during the MP and LP, the largest increase in precipitation occurs during winter in the LP for RCP8.5, and the RC exceeds $20 \%$.

There is model uncertainty of SWE simulation in the 21 st century, especially for RCP8.5, this is illustrated in Fig. 8, which also shows the range of uncertainty in the mid-low emission scenario. However, despite model uncertainty, annual SWE still exhibits a consistent and significant decline for each of the three RCPs, with a linear trend of $-0.54 \mathrm{~kg} \mathrm{~m}^{-2} / 10 \mathrm{a}$ for RCP2.6, $-1.09 \mathrm{~kg} \mathrm{~m}^{-2} / 10 \mathrm{a}$ for RCP4.5 and $-2.05 \mathrm{~kg} \mathrm{~m}^{-2} / 10$ a for RCP8.5 (Table 3). Figure 8 also shows that the negative trend in SWE gradu- 
Table 4. Partial correlations between mean annual SWE and both mean temperature $(T)$ and precipitation $(P)$ over Northern Hemisphere land for three RCPs. RP, EP, MP, and LP represent the periods 1986-2005, 2016-2035, 2046-2065, and 2080-2099, respectively.

\begin{tabular}{|c|c|c|c|c|c|c|c|c|c|c|c|}
\hline \multirow{2}{*}{ Month } & & \multirow[b]{2}{*}{$\mathrm{RP}$} & \multicolumn{3}{|c|}{ RCP2.6 } & \multicolumn{3}{|c|}{ RCP4.5 } & \multicolumn{3}{|c|}{ RCP8.5 } \\
\hline & & & EP & MP & LP & EP & MP & LP & EP & MP & LP \\
\hline \multirow[t]{2}{*}{ Jan. } & $T$ & -0.29 & $-0.59^{*}$ & -0.25 & -0.1 & $-0.54^{*}$ & $-0.44^{*}$ & $-0.52^{*}$ & $-0.45^{*}$ & $-0.38^{*}$ & -0.31 \\
\hline & $P$ & -0.13 & -0.22 & -0.05 & -0.13 & 0.1 & 0 & -0.14 & 0.05 & -0.05 & -0.05 \\
\hline \multirow[t]{2}{*}{ Feb. } & $T$ & $-0.42^{*}$ & -0.2 & -0.1 & $-0.37^{*}$ & -0.25 & $-0.76^{*}$ & $-0.38^{*}$ & $-0.51^{*}$ & $-0.39^{*}$ & -0.28 \\
\hline & $P$ & 0.05 & -0.17 & -0.11 & 0.04 & -0.11 & 0.18 & 0.09 & 0.02 & -0.05 & -0.11 \\
\hline \multirow[t]{2}{*}{ Mar. } & $T$ & -0.22 & -0.26 & -0.24 & $-0.54^{*}$ & $-0.42^{*}$ & -0.17 & $-0.56^{*}$ & $-0.4^{*}$ & $-0.4^{*}$ & $-0.4^{*}$ \\
\hline & $P$ & -0.07 & -0.03 & -0.09 & 0.22 & -0.05 & -0.18 & 0.05 & -0.02 & -0.03 & 0.01 \\
\hline \multirow[t]{2}{*}{ Apr. } & $T$ & $-0.38^{*}$ & -0.31 & -0.14 & $-0.38^{*}$ & $-0.37^{*}$ & $-0.49^{*}$ & $-0.51^{*}$ & $-0.49^{*}$ & $-0.38^{*}$ & $-0.38^{*}$ \\
\hline & $P$ & -0.06 & -0.1 & 0.02 & -0.01 & -0.09 & 0.09 & 0.09 & 0.11 & -0.08 & -0.05 \\
\hline \multirow[t]{2}{*}{ May } & $T$ & $-0.36^{*}$ & -0.33 & -0.31 & -0.34 & -0.31 & $-0.46^{*}$ & $-0.5^{*}$ & $-0.48^{*}$ & $-0.42^{*}$ & $-0.41 *$ \\
\hline & $P$ & -0.07 & -0.1 & -0.38 & -0.06 & -0.2 & 0.07 & 0.09 & 0.1 & -0.06 & -0.01 \\
\hline \multirow[t]{2}{*}{ Jun. } & $T$ & $-0.43^{*}$ & -0.33 & $-0.57^{*}$ & -0.07 & -0.26 & $-0.46^{*}$ & -0.08 & $-0.45^{*}$ & $-0.39^{*}$ & $-0.38^{*}$ \\
\hline & $P$ & -0.07 & -0.09 & 0.12 & -0.06 & -0.11 & 0.11 & -0.27 & -0.04 & 0.02 & -0.05 \\
\hline \multirow{2}{*}{ Jul. } & $T$ & $-0.48^{*}$ & $-0.48^{*}$ & 0.27 & -0.26 & $-0.56^{*}$ & $-0.54^{*}$ & $-0.51^{*}$ & -0.04 & $-0.46^{*}$ & -0.24 \\
\hline & $P$ & -0.11 & 0 & -0.2 & -0.14 & -0.08 & -0.02 & 0.05 & 0.02 & -0.09 & -0.02 \\
\hline \multirow[t]{2}{*}{ Aug. } & $T$ & -0.33 & $-0.48^{*}$ & $-0.36^{*}$ & -0.21 & $-0.48^{*}$ & $-0.38^{*}$ & -0.29 & $-0.47^{*}$ & $-0.48^{*}$ & $-0.4^{*}$ \\
\hline & $P$ & -0.07 & -0.25 & -0.06 & -0.03 & 0 & 0 & -0.02 & -0.18 & 0 & -0.06 \\
\hline \multirow[t]{2}{*}{ Sep. } & $T$ & -0.35 & $-0.44^{*}$ & $-0.39^{*}$ & 0.13 & -0.3 & -0.1 & $-0.59^{*}$ & -0.27 & -0.24 & -0.34 \\
\hline & $P$ & -0.05 & -0.13 & -0.01 & -0.14 & -0.17 & -0.07 & 0.14 & -0.07 & -0.15 & -0.04 \\
\hline \multirow[t]{2}{*}{ Oct. } & $T$ & -0.35 & $-0.53^{*}$ & 0.18 & 0.16 & $-0.47^{*}$ & -0.21 & $-0.5^{*}$ & -0.33 & -0.28 & -0.25 \\
\hline & $P$ & -0.08 & 0 & -0.09 & -0.52 & -0.03 & 0.06 & 0.07 & -0.1 & -0.06 & -0.06 \\
\hline \multirow[t]{2}{*}{ Nov. } & $T$ & $-0.43^{*}$ & $-0.36^{*}$ & -0.07 & 0.01 & $-0.53^{*}$ & $-0.47^{*}$ & -0.21 & -0.29 & -0.21 & -0.33 \\
\hline & $P$ & -0.05 & -0.11 & -0.09 & -0.28 & 0.15 & -0.05 & -0.2 & -0.03 & -0.17 & 0 \\
\hline \multirow[t]{2}{*}{ Dec. } & $T$ & -0.25 & $-0.5^{*}$ & -0.12 & 0.08 & -0.27 & $-0.58^{*}$ & -0.35 & -0.34 & -0.28 & -0.28 \\
\hline & $P$ & -0.12 & -0.05 & -0.01 & -0.29 & -0.16 & -0.05 & -0.19 & -0.03 & -0.05 & 0.04 \\
\hline
\end{tabular}

Note: ${ }^{*}$ values exceed the $95 \%$ significance test.

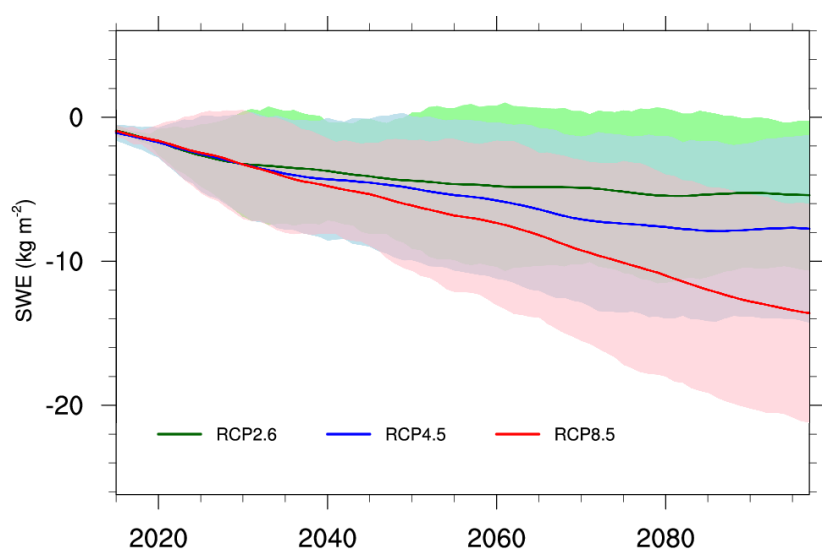

Figure 8. Projected changes in mean annual SWE over Northern Hemisphere land during the 21 st century for all three RCPs (green: RCP2.6; blue: RCP4.5; red: RCP8.5). The mean value for the 19862005 reference period is subtracted from all values. Also shown is the multi-model mean for all available models for each scenario. The 10-year running average was derived for each model before calculating the multi-model mean. Shaded areas denote the intermodel standard deviation for each ensemble mean. ally begins to level out for RCP2.6, and weakens somewhat for RCP4.5. For RCP8.5, however, SWE continues to decline beyond the end of the 21 st century, which agrees with projections of snow cover extent (Zhu and Dong, 2013; BrutelVuilmet et al., 2013).

\section{Contribution of temperature and precipitation to SWE change}

To identify the relative contributions of temperature and precipitation to changes in SWE, we calculate the partial correlation between SWE and temperature as well as between SWE and precipitation during the RP, EP, MP and LP for three RCPs (Table 4). SWE has a strong negative partial correlation with temperature throughout the 21 st century, but the correlation between SWE and precipitation was not statistically significant. The negative partial correlation for RCP8.5 decreases from the EP to the LP in the winter half-year, indicating that there is less snow to melt when the air temperature increases to a certain level. We also note that the partial correlation between SWE and temperature during the spring uniformly passes the $90 \%$ significance test during the EP, 


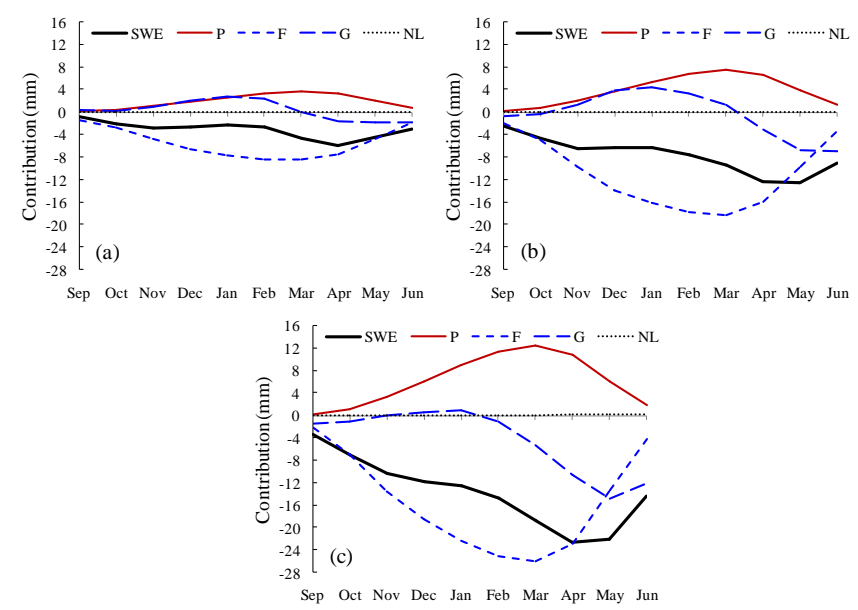

Figure 9. Mean changes in SWE decomposed using Eq. (4) to show the contribution of changes in precipitation $(\Delta P)$, the fraction of solid precipitation $(\Delta F)$, the fraction of accumulated snowfall that remains on the ground $(\Delta G)$, and nonlinear terms (NL) during the period of 2016-2035 (a), 2046-2065 (b), and 2080-2099 (c) for RCP8.5, relative to the 1986-2005 reference period.

MP and LP for RCP8.5, resulting in a persistent decline in springtime SWE, despite the increase in precipitation.

Relative to 1986-2005, the largest absolute decline in simulated SWE also occurs in spring, indicating that the decrease in SWE is related to earlier temperature-driven snowmelt. This result agrees with Räisänen (2008) who proposed that changes in snow conditions would likely depend on presentday temperature. With the increasing temperature, the sensitivity of SWE to temperature averaged over the $\mathrm{NH}$ gradually increases from the EP to the LP for the same RCP (not shown).

Temperature increase may change the water cycle and rain-snow ratio (fraction of solid precipitation), and will act to increase the rate of snow melt (fraction of accumulated snowfall). Actually, as shown by Eq. (4), SWE can be affected by changes in total precipitation, the fraction of precipitation that falls as snow and the fraction of accumulated snowfall that has not melted. Räisänen (2008) used CMIP3 model simulations to analyze the contributions of the above factors to SWE in Finland and eastern Siberia, and suggested that the major contributor to the change in SWE varies regionally, thus, over the whole $\mathrm{NH}$, how about the effects of total precipitation, snowfall and accumulated snowfall on SWE during the different periods of the 21 st century?

Figure 9 shows the contributions of total precipitation, snowfall and accumulated snowfall to the changes in SWE following Eq. (4; Räisänen, 2008) for three RCPs during three periods of 21 st century. During the EP, total precipitation shows an increase in all months, but snowfall decreases in all months, as well as SWE reduce in all month, this indicates that the competition between liquid and solid precipitation influences the change in SWE with the temperature in- crease leads to SWE decrease. Because the magnitude of the decrease in snowfall is larger than the increase in total precipitation, the reduction in SWE is attributed to changes in the fraction of precipitation that falls as snow. The contributions of total precipitation, snowfall and accumulated snowfall grow larger with time. In general, from September to May in the next year, the change (increase/decrease) in SWE is generally related to change (increase/decrease) in snowfall, but after May increased melting efficiency dominates the change in SWE. Figure 9 shows, during the LP, temperature increases cause the reduction in accumulated snowfall to be larger than the decreasing in snowfall after May, so that the former becomes the main control on SWE.

\section{Summary and conclusions}

We employed 20 CMIP5 climate models to investigate projected changes in SWE for the 21st century under three different RCPs. The results show a decrease in mean annual SWE for all three RCPs over much of the NH landmass relative to the RP. The most significant reductions occur over the southern latitude, with an increase over Siberia, however, the overall pattern in the NH is one of declining SWE. The multimodel ensemble suggests that the magnitude of reductions in SWE are strongly related to future emissions: negative trends in SWE level out before the end of the 21st century under RCP2.6, but continue to decline beyond the end of the 21st century for RCP8.5.

Partial correlations between SWE and both temperature and precipitation indicate that decreases in SWE can be primarily attributed to increasing temperatures and decomposition of the SWE change signal showed that reduction in SWE is predominately attributed to warming-induced reductions in the fraction of precipitation that falls as snow from September to May.

The spatial pattern of projected mean annual SWE change shows a clear north-south gradient with the largest relative reductions over more southern latitudes. The seasonal pattern of projected changes shows the largest changes occurring during the spring-summer period with the lowest changes for annual maximum SWE. This underscores the need to examine SWE changes over the entire season. 
Author contributions. C. H. Wang contributed to the idea and conception of this study, analysis of the result and arrangement the framework of the manuscript. H. X. Shi carried out the analysis of the data and writing the manuscript with the assistance of C. H. Wang.

Acknowledgements. This work was supported by the National Key Basic Research Program of China (2013CBA01808), National Natural Science Foundation of China (no. 91437217, 41275061, 41440035, 41471034). The basic science research project in Lanzhou University (lzujbky-2015-k03). The snow water equivalent data used in this study are from the European Space Agency (ESA) GlobSnow product and CMIP5 model outputs. We appreciate editor Brown Ross's professional suggestions, we also appreciate the constructive comments and suggestions of the anonymous reviewers.

Edited by: R. Brown

\section{References}

Brown, R. D. and Mote, P. W. : The response of Northern Hemisphere snow cover to a changing climate, J. Climate, 22, 21242145, 2009.

Brutel-Vuilmet, C., Ménégoz, M., and Krinner, G.: An analysis of present and future seasonal Northern Hemisphere land snow cover simulated by CMIP5 coupled climate models, The Cryosphere, 7, 67-80, doi:10.5194/tc-7-67-2013, 2013.

Chen, S. B., Liu, Y. F., and Thomas, A.: Climatic change on the Tibetan Plateau: potential evapotranspiration trends from 19612000, Climatic Change, 76, 291-319, 2006.

Collins, M., Knutti, R., Arblaster, J., Dufresne, J. L., Fichefet,T., Friedlingstein,P., Gao, X., Gutowski, W. J., Johns,T., Krinner, G., Shongwe, M., Tebaldi,C., Weaver, A. J., and Wehner, M.: Long-term Climate Change: Projections, Commitments and Irreversibility, in: Climate Change 2013: The Physical Science Basis. Contribution of Working Group I to the Fifth Assessment Report of the Intergovernmental Panel on Climate Change, edited by: Stocker, T. F., Qin, D., Plattner, G.-K., Tignor, M., Allen, S. K., Boschung, J., Nauels, A., Xia, Y., Bex, V., and Midgley, P. M., Cambridge University Press, Cambridge, United Kingdom and New York, NY, 1031-1136, USA, 2013.

Falarz, M.: Long-term variability in reconstructed and observed snow cover over the last 100 winter seasons in Cracow and $\mathrm{Za}$ kopane (South Poland), Climate Research, 19, 247-256, 2002.

Groisman, P. Y., Knight, R. W., Karl, T. R., Easterling, D. R., Sun, B., and Lawrimore, J. H.: Contemporary changes of the hydrological cycle over the contiguous United States: Trends derived from in situ observations, J. Hydrometeorol., 5, 64-85, 2004.

Hancock, S., Baxter, R., Evans, J., and Huntley, B.: Evaluating global snow water equivalent products for testing land surface models, Remote Sens. Environ, 128, 107-117, 2013.

Ji, Z. M. and Kang, S. C.: Projection of snow cover changes over China under RCPs scenarios, Clim. Dynam., 41, 589-600, 2012.

Liu, X. X. and Chen, B. D.: Climatic warming in the Tibetan Plateau during recent decades, Int. J. Climatol., 20, 1729-1742, 2000.
Maloney, E. D., Camargo, S. J., Chang, E., Colle, B., Fu, R., Geil, K. L., Hu, Q., Jiang, X. N., Johnson, N., Karnauskas, K. B., Kinter, J., Kirtman, B., Kumar, S., Langenbrunner, B., Lombardo, K., Long, L. N., Mariotti, A., Meyerson, J. E., Mo, K. C., Neelin, J. D., Pan, Z. T., Seager, R., Serra, Y., Seth, A., Sheffield, J., Stroeve, J., Thibeault, J., Xie, S. P., Wang, C. Z., Wyman, B., and Zhao, M.: North American Climate in CMIP5 Experiments: Part III: Assessment of 21st Century Projections, J. Climate, 27, 2230-2270, 2014.

Mote, P. W.: Climate-Driven Variability and Trends in Mountain Snowpack in Western North America, J. Climate, 19, 62096220, 2006.

Mote, P. W., Hamlet, A. F., Clark, M. P., and Lettenmaier, D. P.: Declining mountain snowpack in western North America, B. Am. Meteor. Soc., 86, 39-49, 2005.

Pithan, F. and Mauritsen, T.: Arctic amplification dominated by temperature feedbacks in contemporary climate models, Nat. Geosci., 7, 181-184, 2014.

Räisänen, J. : Warmer climate: less or more snow?, Climate Dynamics, 30, 307-319, 2008.

Scherrer, S. C., Appenzeller, C., and Laternser, M.: Trends in Swiss alpine snow days-the role of local and large scale climate variability, Geophys. Res. Lett., 31, L13215, doi:10.1029/2004GL020255, 2004.

Stewart, I. T., Cayan, D. R., and Dettinger, M. D.: Changes towards earlier streamflow timing across western North American, J. Climate, 18, 1136-1-155, 2005.

Takala, M., Luojus, K., Pulliainen, J., Derksen, C., Lemmetyinen, J., Kärnä, J. P., Koskinen, J., and Bojkov, B.: Estimating northern hemisphere snow water equivalent for climate research through assimilation of space-borne radiometer data and ground-based measurements, Remote Sens. Environ., 115, 3517-3529, 2011.

Taylor, K. E.: Summarizing multiple aspects of model performance in a single diagram, J. Geophys. Res., 106, 7183-7192, 2001.

Taylor, K. E., Stouffer, R. J., and Meehl, G. A.: An Overview of CMIP5 and the experiment design, B. Am. Meteor. Soc., 93, 485-498, 2012.

Tong, J., Déry, S. J., Jackson, P. L., and Derksen, C.: Testing snow water equivalent retrieval algorithms for passive microwave remote sensing in an alpine watershed of western Canada, Can. J. Remote Sens., 36, S74-S86, doi:10.5589/m10-009, 2010.

Vaughan, D. G., Comiso, J. C., Allison, I., Carrasco, J., Kaser, G., Kwok, R., Mote, P., Murray, T., Paul,F., Ren, J., Rignot, E., Solomina, O., Steffen, K., and Zhang, T.: Observations: Cryosphere, in: Climate Change 2013: The Physical Science Basis. Contribution of Working Group I to the Fifth Assessment Report of the Intergovernmental Panel on Climate Change, edited by: Stocker, T. F., Qin, D., Plattner, G.-K., Tignor, M., Allen, S. K., Boschung, J., Nauels, A., Xia, Y., Bex, V., and Midgley, P. M., Cambridge University Press, Cambridge, United Kingdom and New York, NY, USA, 319-382, 2013.

Vavrus, S.: The role of terrestrial snow cover in the climate system, Clim. Dynam., 29, 73-88, 2007.

Vojtek, M., Faško, P., and Šťastný, P.: Some selected snow climate trends in Slovakia with respect to altitude, Acta Meteorologica Universitatis Comenianae, 32, 17-27, 2003.

Wang, C. H., Wu, Y. P., and Cui, Y.: Evaluating the progress of the CMIP and its application prospect in China, Adv. Earth Sci., 24, 461-468, 2009. 
Wang, C. H., Li, J., and Xu, X. G.: University of Quasi-3-year period of temperature in last 50 years and change in next 20 year in China, Plateau Meteorol., 31, 126-136, 2012.

Wang, Z. L. and Wang, C. H.: Predicting the snow water equivalent over China in the next 40 years based on climate models from IPCC AR4, J. Glaciol. Geocryol., 34, 1273-1283, 2012.

Wang, Z. L., Wang C. H., and Shen, Y. P.: A prediction of snow cover depth in the Northern Xinjiang in the next 50 years, J. Glaciol. Geocryol., 32, 1059-1065, 2010.
Zhu, X. and Dong, W. J. : Evaluation and projection of Northern Hemisphere March-April snow cover area simulated by CMIP5 coupled climate models, Progressus Inquisitiones DE Mutatione Climatis, 9, 173-180, 2013. 